\title{
Comparison and Summarization of Measurement Methods of Human Capital Stock
}

\author{
Zhili Ren \\ Shannxi Normal University SNNU Xi'an, China
}

\author{
Pei Zhang \\ Shannxi Normal University SNNU Xi'an, China
}

\begin{abstract}
This paper first analyzes three representative methods of human capital stock measurement methods, wherein each method of data involved in the index selection problem, elaborates on the missing data estimation problem, and then analyzes and compares the estimation results. Finally, the paper reaches a conclusion that there are many differences between calculation results. Therefore, it still requires a long-term exploration and research to achieve a more accurate estimate of human capital.
\end{abstract}

Keywords-Production Function; The Stock of Human Capital; The Perpetual Inventory Method; The Cost Weighted Method

\section{INTRODUCTION}

Estimates of potential output, the production function method is one of the most widely used measure, its advantage is that this method is based on the theories of economic growth, from the perspective of economic supply, fully consider the inputs to the contribution of economic growth, rather than merely rely on the statistical relationship between the variables, economic theory as the support.

Scholars in the study of Chinese production function method is used to mainly, Lisheng Shen(1999), Qingwang Guo and Junxue Jia(2004), Meibo Huang and Chaofeng Lv(2010), Hongfei Yu and Yimin Tian (2013), Han Guo and Baoping Ren (2014) Guopei Wu, Weibin Wang and Xining Zhang (2015), etc. Using production function method to estimate potential output is studied using the Cobb-Douglas production function were analyzed, and the improved Cobb-Douglas production function of general form as follows:

$$
\mathrm{Y}=\mathrm{A} K^{\alpha}(h L)^{\beta}
$$

Where $\mathrm{Y}$ is actual output, $\mathrm{A}$ is total factor productivity (TFP), $\mathrm{K}$ is capital input, $\mathrm{h}$ is the quality of labor input and $\mathrm{L}$ is the quantity of labor input. Therefore, $h * \mathrm{~L}$ represents the meaning of human capital, $\alpha$ and $\beta$ respectively represent the output elasticity of capital and labor.

However, the method of data quality request is higher, and the human capital cannot direct access to data, need through the correlation algorithm to measure, the existing literature on human capital measurement method are many, the purpose of this paper is to measure method of three representative carding and analysis, so as to provide reference for further research.

\section{Measurement Method of Human Capital Stock}

\section{A. The Perpetual Inventory Method}

The Chinese human capital stock count: 1978 2007, Binlong Jiao, Zhiming Jiao (2010), this article defines human capital as education, health, scientific research, training, and transfer the sum of 5 kinds of human capital the perpetual inventory method is adopted as the basic method of human capital stock accounting, its computation formula is as follows:

$$
H_{t}=(1-\delta) H_{t-1}+I_{t}
$$

Where $\mathrm{H}$ is the stock of human capital, I is the human capital investment, $\delta$ is the depreciation rate of human capital, $\mathrm{t}$ represents time. Five kinds of human capital were estimated respectively by education, health, scientific research, training and migration, and then the human capital stock was added up.

1) Estimates of the Stock of Human Capital in the Base Year

Assume some kind of the human capital stock for $\mathrm{X}$ in China in 1977, this kind of human capital investment in1978 and 1979 is known A and B, respectively, the total amount of the residents' income is known $\mathrm{C}$ and $\mathrm{D}$, respectively, the depreciation rate of human capital as $\delta$, supposing the human capital in 1978 and 1979 revenues than the same, getting the following formula:

$$
[(1-\delta) \mathrm{X}+\mathrm{A}] / \mathrm{C}=\{[(1-\delta) \mathrm{X}+\mathrm{A}](1-\delta)+\mathrm{B}\} / \mathrm{D} .
$$

So, the human capital stock of China in 1977 can be calculated.

2) Selection of Various Human Capital Investment Indicators in the Current Period

For education human capital, the annual education total fund is used to represent the human capital investment of education in that year. The total expenditure of education from 1978 to 1985 was spent on education through the national finance compiled by the statistical data of the 55th year of the People's Republic of China. The total amount of education from 1992 to 2007 shall be the total amount of education in China statistical yearbook. The total funds of education from 1986 to 1991 were fitted according to the relationship between the expenditure of education from the national finance and the total funds of education in previous years.

For health human capital, the annual total health fund is used to represent the investment of health human capital in that year. The data source is China health statistical yearbook 2007. 
For the human capital of scientific research, the total expenditure of scientific research is used to represent the investment of human capital of scientific research in that year. Data from 1978 to 2004 were collected from the compilation of statistical data of the 55th year of the People's Republic of China, and data from 2005 to 2007 were collected from the China statistical yearbook from 2006 to 2008.

For the training of human capital, the existing data cannot be used directly. For the convenience of technical treatment, $1.5 \%$ of the total wages of enterprise employees is adopted to replace the input of on-the-job training of employees.

For migration of human capital, the use of China's employment of township enterprises from 1978 to 1992 half instead of a number of rural population flow, 1993 data from the national bureau of statistics, and so on, mainly is the opportunity cost and further assume that the migration cost, less costly and migration itself. Therefore, the annual migration of human capital is the product of the number of migrant workers and the per capita net income of rural residents.

\section{3) The Human Capital Investment Price Index}

For the human capital investment price index, GDP deflator is used to replace the real human capital investment price index.

\section{4) The Choice of Depreciation Rate}

The straight-line depreciation method in accounting is used for reference, that is, a kind of capital goods depreciates from the time it is finished producing and put into use, until it exits completely and does not participate in production, the depreciation rate is zero. For human capital, assumes that residents from the human capital of China to accept the human capital investment to depreciation, to 60 out of the labour market, and the depreciation of human capital stock oneself completely is zero, so that we can get the following relationship:

The depreciation rate is equal to 1 over the average life of human capital; the average life of human capital is equal to 60 minus the average time spent on human capital.

For education, the Chinese people began to accept education for 8 years old, is the average time from 1978 to 2007 Chinese residents' average education years take intermediate values of about 8 years, Chinese residents education human capital investment can be obtained using the average time is about 16 years of age, and education of human capital depreciation rate is $2.27 \%$.

For health, the life expectancy of health human capital is expressed as 60 minus the average age of Chinese residents. According to China's population census data, the average age of the Chinese population increased slightly from 1978 to 2007. At the same time, medical research has shown that people's health declines from the age of 30.Therefore, the depreciation rate of health human capital $=1 /(60$-the average age of Chinese residents) $=3.33 \%$.

For scientific research, this paper uses scientific research product patent protection to illustrate how the average life span for the research of human capital, by measuring the scientific research products from the available to the end of the period, gains to approximate the average life expectancy of human capital of scientific research. Therefore, the average life of human capital in scientific research is measured by taking the approximate mean value for 15 years, so that the depreciation rate of human capital in scientific research is $6.67 \%$.

For training, as well as health human capital, accompanied by one of all the career characteristics, therefore, using the same method, the training of human capital depreciation rate $=$ $1 /$ (average age 60-Chinese residents $)=3.33 \%$.

For migration, due to the migration of human capital measurement is mainly based on opportunity cost, therefore, assumes that the migration of human capital depreciation in the end, the migration has no accumulating human capital, that the migration of human capital depreciation rate of $100 \%$.

\section{B. The Improved Mulligan and Sala-i-Martin's method}

The human capital and economic growth in China: 1978 2030, Run Liang (2011), this article the author choose social overall labor according to certain characteristics can be divided into different groups, respectively, to predict the number of groups and estimate the labor income of each group, add up to get the labor income of the whole society.

Proceeding from China's actual situation, according to age, gender, level of education and urban and rural dimension to labor division, the first to estimate the calendar year of 1978 2030 points, age, gender, level of education and urban and rural population, to calculate the overall human capital stock.

For 1978 2030 years age, gender, level of education and urban and rural population of measure, demography has developed a set of relatively mature method to the unknown year population estimates and projections, this paper uses 1982,1990,2000 census data, these three times by building population life table, first of all points which estimates the population of the age and gender, and combined with the rural and urban education at all levels throughout the years include population census micro data transfer between urban and rural areas in the population according to age. The distribution of gender and education degree is used to estimate and predict the number of people aged, gender, education degree and urban and rural population over the years.

To solve the problem of income of different groups over the years, the following Mincer equation was used to estimate the urban and rural workers and workers of different genders.

$$
\begin{aligned}
& \ln \left(\text { wage }_{i j t}\right)=\alpha_{i j t}+\beta_{i j t} \cdot E d u_{i j t}+\gamma_{1 i j t} \cdot \operatorname{Exp}_{i j t}+\gamma_{2 i j t} \\
& \operatorname{xxp}_{i j t}+\varepsilon_{i j t}
\end{aligned}
$$

Where $\mathrm{i}$ represents gender, $\mathrm{j}$ represents urban or rural, $\mathrm{t}$ represents time.

$\ln \left(\right.$ wage $\left._{i j t}\right)$ is the $\log$ of wages, $E d u_{i j t}$ is the average education years, $\operatorname{Exp}_{i j t}$ is potential work experience, $\varepsilon_{i j t}$ is the random error, $\alpha_{i j t}$ represents the average wage log of workers with gender $i$ in the year of $\mathrm{t}$ and without education or work experience in area $\mathrm{j}, \beta_{i j t}$ represents the education rate of return for the corresponding gender and region in the year of $\mathrm{t}, \gamma_{1 i j t}$ and $\gamma_{2 i j t}$ are return parameters related to work experience. 
If with a lack of education and no work experience of the rural female labor force as our unit of human capital, human capital of rural and urban workers decision equation should be as follows:

The rural female:

$$
\ln \left(H_{f r t}\right)=\beta_{f r t} \cdot E d u_{f r t}+\gamma_{1 f r t} \cdot \operatorname{Exp}_{f r t}+\gamma_{2 f r t} \cdot \operatorname{Exp}_{f r t}^{2}
$$

The rural male:

$$
\begin{aligned}
& \ln \left(H_{m r t}\right)=\alpha_{m r t}-\alpha_{f r t}+\beta_{m r t} \cdot E d u_{m r t}+\gamma_{1 m r t} \bullet \\
& \operatorname{Exp}_{m r t}+\gamma_{2 m r t} \cdot \operatorname{Exp}_{m r t}^{2}
\end{aligned}
$$

The urban female:

$$
\begin{aligned}
& \ln \left(H_{f u t}\right)=\alpha_{f u t}-\alpha_{f r t}+\beta_{f u t} \cdot E d u_{f u t}+\gamma_{1 f u t} \cdot \operatorname{Exp}_{f u t}+\gamma_{2 f u t} \\
& \cdot \operatorname{Exp}_{\text {fut }}^{2}
\end{aligned}
$$

The urban male:

$$
\begin{gathered}
\ln \left(H_{\text {mut }}\right)=\alpha_{\text {mut }}-\alpha_{f r t}+\beta_{\text {mut }} \cdot E d u_{\text {mut }}+\gamma_{1 m u t} \bullet \\
\operatorname{Exp}_{\text {mut }}+\gamma_{2 m u t} \cdot \operatorname{Exp}_{\text {mut }}^{2}
\end{gathered}
$$

Where, $H_{i j t}$ represents the human capital of the corresponding gender and urban and rural individuals in the year of $\mathrm{t}$ respectively. The human capital $\mathrm{H}$ of rural women without education or work experience has been standardized to 1 .

First of all, to estimate the type (1) it is concluded that the coefficient of linear regression according to the time trend, the coefficient of the calendar year $1978 \sim 2030$ is obtained the fitting values, then, to use the fitting values and above human capital decided to equation (2) (5) points throughout the years of age, gender, level of education and urban and rural individual human capital, according to the number of each group aggregation again get the total stock of human capital.

\section{The Cost Weighted Method}

The reestimation of China's human capital stock: 1978 2011, Hongfang Qiao, Lisheng Shen (2015), this paper used the cost weighting method to estimate China's human capital stock from 1978 to 2011.

\section{1) Weight Selection in Labor Force Weighting}

For education investment, this paper selected the workers, as the carrier of human capital, only to include this part of the group of education spending in the range of estimates of human capital, at the same time, considering the education expenditure of hysteresis backstepping method is used to calculate a degree level workforce education investment.

As for the expenditure on health care and education and entertainment, the author thinks that the expenditure only refers to the expenditure on health care for the real labor force. In order to keep the consistency of the calculation, the main body of the expenditure on culture, education and entertainment is also limited to the real practitioners.

As for the expenditure caused by population migration, the article estimates the national human capital stock. Due to the flow of human capital between provinces, and the resulting population migration spending, just changed the regional distribution of human capital did not change the country's stock of human capital, and therefore does not consider cost of inter-provincial migration of the population. At the same time, in general, China's population migration rate is low, so the cost of migration is ignored.

The opportunity cost of human capital investment is also ignored in order to ensure the comparability between human capital and physical capital and other capital data.

\section{2) The Basic Assumption}

Because the difference in human capital can usually be reflected by accepting different education degrees, the article assumes that employees' education degree is the sign of their human capital.

The laborer completely in accordance with the system requirements and regulations of the state to obtain corresponding qualifications, then can be a primary, junior high school education, a high school diploma, college degree and a graduate degree of human capital formation takes six years respectively, nine years, 12 years, 16 and 19 years.

From personnel of course of the last record of formal schooling is a one-time and remains the same in real life, some workers may be intermittent type to obtain the final degree, but the actual education under the circumstance of fixed number of year on the premise of basic data missing is unable to accurately measure and measure in order to make things simple, ignore these cases, assume that the employees did not interrupt the learning, and once after the last record of formal schooling, then into the labor market, and has kept the record of formal schooling level remains the same.

The middle number of each group is the age of representative employees. The age of employees is divided into 11 groups :16-19, 20-24, 25-29, 30-34, 35-39, 40-44, $45-49,50-54,55-59,60-64$ and over 65.For each age group, the median age was selected as the age of representative employees, and the age of employees over 65 was unified to 65.

\section{3) The Computational Formula}

Based on the above assumptions, the estimated cost of education investment of human capital, the basic idea is according to the calendar year the degree distribution of the typical age labor retracing their respectively in the primary school, middle school, high school and college education spending by stage of education, culture to a certain age, education level of existing labor takes the education cost of total spending, at the same time, the cost of education, the author thinks that should also join the staff of health care and total spending on education and entertainment. Taking the sum of the above three types of investment expenditures as the weight, the number of employees at all levels of education is weighted and summed up, so as to estimate the total amount of human capital in China. The calculation formula is as follows:

$$
\begin{array}{r}
H_{t} \quad=\quad \sum_{j} L_{t 1 j} \\
\sum_{s=j-22}^{j-24} R E M T_{t-s, j}+\sum_{s=j-18}^{j-21} R E U T_{t-s, j}+\sum_{s=j-15}^{j-17} R E S T_{t-s, j}+ \\
\left.\sum_{s=j-12}^{j-14} R E J T_{t-s, j}+\sum_{s=j-6}^{j-11} R E P T_{t-s, j}+R H C E_{t}+R C E E_{t}\right)+ \\
\sum_{j} L_{t 2 j}
\end{array} .
$$




$$
\begin{array}{r}
\left(\sum_{s=j-18}^{j-21} R E U T_{t-s, j}+\sum_{s=j-15}^{j-17} R E S T_{t-s, j}+\sum_{s=j-12}^{j-14} R E J T_{t-s, j}+\right. \\
\left.\sum_{s=j-6}^{j-11} R E P T_{t-s, j}+R H C E_{t}+R C E E_{t}\right)+\sum_{j} L_{t 3 j} \cdot \\
\left(\sum_{s=j-15}^{j-17} R E S T_{t-s, j}+\sum_{s=j-12}^{j-14} R E J T_{t-s, j}+\right. \\
\left.\sum_{s=j-6}^{j-11} R E P T_{t-s, j}+R H C E_{t}+R C E E_{t}\right)+\sum_{j} L_{t 4 j} \cdot \\
\left(\sum_{s=j-12}^{j-14} R E J T_{t-s, j}+\sum_{s=j-6}^{j-11} R E P T_{t-s, j}+R H C E_{t}+\right. \\
\left.R C E E_{t}\right)+\sum_{j} L_{t 5 j} \cdot\left(\sum_{s=j-6}^{j-11} R E P T_{t-s, j}+R H C E_{t}+\right. \\
\left.R C E E_{t}\right)+\sum_{j} L_{t 6 j} \cdot\left(R H C E_{t}+R C E E_{t}\right)
\end{array}
$$

Where $\mathrm{H}$ is the stock of human capital, $L_{t i j}$ represents the number of employees at the educational level of $j$ age $i$ in the year of $t, i=1,2,3,4,5,6$, it refers to the six academic levels of postgraduate, undergraduate, high school, middle school, primary school and non-school education respectively, $R E M T_{t}, R E U T_{t}, R E S T_{t}, R E J T_{t}, R E P T_{t}, \quad R H C E_{t}$ and $R C E E_{t}$ respectively shows that graduate students, college students, high school students, middle school students and primary school students all have education funds, as well as per capita medical care and per capita cultural, educational and entertainment expenses. Per capita spending on health care and education and entertainment does not differentiate between the educational levels of the workforce.

\section{CONCLUSIONS}

With larger space, this paper has a detailed expounds the three representative about human capital stock measurement method, as well as the calculation method of relevant data in the process of selection, and the lack of data processing method also has carried on the detailed description. We is not hard to find, for the measurement of human capital stock, in addition to the most commonly used method of fixed number of year of the education, estimation method, there are some other useful material capital stock often use the perpetual inventory method to estimate the stock of human capital, useful improved Mulligan and Sala-I-Martin method to estimate the human capital stock, also useful cost weighting method to estimate the human capital stock, however, at present the problems of a measure, is to estimate the capital stock of differences. For the production function method is used to estimate potential output and other issues related to the researchers, is certainly a very tricky problems, inaccurate data is not reliable, will directly affect the ultimate estimate results can be reference value, therefore, on the whole, how to make human capital of relatively more accurate estimates, will remain in the process of long-term exploration and development.

\section{REFERENCES}

[1] Lisheng Shen. Estimation of the change trend of China's potential economic growth rate $[\mathrm{J}]$. Research on quantitative economy, 1999(12):3-6. (In Chinese)

[2] Qingwang Guo, Junxue Jia. Estimation of China's potential output and output gap [J].Economic research, 2004(05):31-39. (In Chinese)

[3] Meibo Hunag,Zhaofeng Lv.Estimation of China's potential output and test of "natural rate hypothesis" [J].Research on quantitative economy, technology and economy,2010,27(07):3-20. (In Chinese)

[4] Hongfei Yu,Yimin Tian. Reestimation of potential output and output gaps in China from 1978 to 2011--based on different production function methods [J]. Financial science,2013(05):85-94. (In Chinese)

[5] Han Guo,Baoping Ren. Structural change,factor output elasticity and China's potential economic growth rate [J].Quantitative economy,2014,31(12):72-84.(In Chinese)

[6] Guopei Wu,Weibin Wang,Xining Zhang.Analysis of China's economic growth potential under the new normal [J].Financial research,2015(08):46-63. (In Chinese)

[7] Binlong Jiao,Zhiming Jiao. The estimation of China's human capital stock: 1978, 2007[J]. Economist, 2010(09):27-33. (In Chinese)

[8] Run Liang. Human capital and economic growth in China: 1978-2030 [A] of degree and graduate management education section of the academic degrees committee of the state council. The national doctoral academic BBS, BBS and macroeconomic young scholars, China's economic growth and structure change, vol. [C]. Management and postgraduate education department, the ministry of education degree: the academic degrees committee of the state council, 2011:17. (In Chinese)

[9] Hongfang Qiao,Lisheng Shen.The reestimation of China's human capital stock :1978-2011 [J]. Shanghai economic research, 2015(07):36-45. (In Chinese)

[10] Lisheng Shen.Analysis on human capital and economic growth [M] Beijing: social sciences academic press, 1999. (In Chinese) 